\title{
THE HYBRID BOND GRAPHS MODELLING ON ANTI LOCK BRAKING SYSTEM SLIDING MODE
}

\author{
Dragana Trajkovic, \\ Slobodan Stefanovic, \\ High School of Applied Professional Studies Vranje, Serbia
}

\begin{abstract}
This paper presents application of the hybrid bond graphs modeling and simulation laboratory anti-lock braking model using Dymola. It is shown on this practical example that the use of Dymola software package will simplify the modeling and simulation. The results and simulation obtained by the hybrid bond graph modeling are presented in this paper.
\end{abstract}

Key words: ABS - anti lock braking system, Hybrid bond graph, Dymola, Simulations.

\section{System description}

In this work we will described prototipe of the ABS brake system made by INTECO, Fig. 1 (Inteco, 2008).

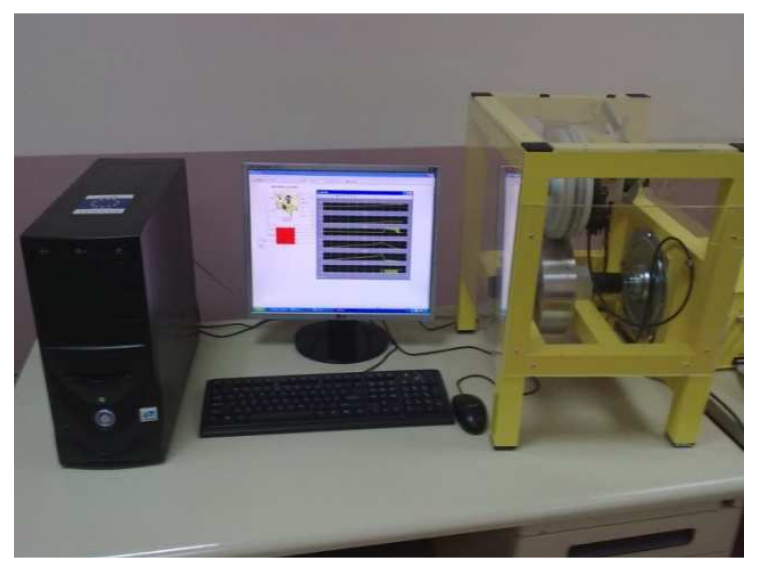

Fig. 1: ABS experimental framework (Inteco)

There is considered only longituional motion and demontrated in lab model.

This INTECO model of an ABS is driven by two DC motors, where the angle rotations is measured by three sensors. This model consists of two rolling wheels: upper wheel is imitation of the vehicle, and lower wheel as imitation of the road.

\section{Mathematical and Bond Graph Model}

An ABS graphical model shown in Fig. 2 has three torques acting on the upper wheel: the braking torque $M_{1}$, the friction torque in the upper bearing and the friction torque among the wheels, torque acting on the lower wheel - the friction torques in the lower bearing and among the wheels.

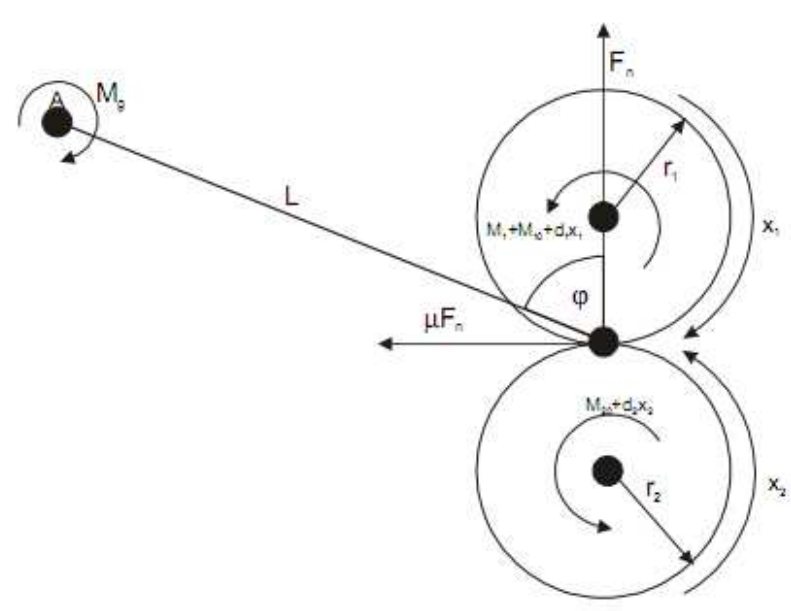

Fig. 2: ABS graphical model

The friction force $F_{n} \mu(\lambda)$ is product of the normal pressing force and the proportional coefficient $\mu(\lambda)$. The following equations are used for described the friction force:

$$
\begin{gathered}
s=\operatorname{sgn}\left(r_{2} x_{2}-r_{1} x_{1}\right) \\
s_{1}=\operatorname{sgn}\left(x_{1}\right) \\
s_{2}=\operatorname{sgn}\left(x_{2}\right)
\end{gathered}
$$

The upper wheel dynamics is described as:

$$
J_{1} \dot{x}_{1}=F_{n} r_{1} s \mu(\lambda)-d_{1} x_{1}-s_{1} M_{10}-s_{1} M_{1}
$$


In the above expression it was used the following notation: $J_{1^{-}}$the moment of inertia of upper wheel, $M_{10}$-the static friction of upper wheel, $\mu(\lambda)$-the coefficient of proportion, $d_{1}$-the viscous friction coefficient.

Dynamics of the lower wheel is showen in next equation:

$$
J_{2} \dot{x}_{2}=-F_{n} r_{2} s \mu(\lambda)-d_{2} x_{2}-s_{2} M_{20}
$$

The moment of the inertia, the viscous friction coefficient and the static friction of the lower wheel are respectively $J_{2}, d_{2}, M_{20}$.

Next marks are used in bond graph modeling:

0 -The zero-junction (0-junction). Each of the power bonds connected to a zero junction have equal efforts. The flows of the power-bonds connected to the zero junction sum to zero, i.e., flow in $^{-}$flow $_{\text {out }}=0$.

1-A one-junction (1-junction). The power bonds connected to a one junction have equal flows. The efforts of the powerbonds connected to the one junction sum to zero, i.e., effort ${ }_{\text {in }}$ - effort ${ }_{\text {out }}=0$.

$m R$-The bond graphic modulated resistor is a modulated passive One Port element. It inherits the effort and flow variables as well as the modulating signal from the modulated passive OnePort. The resisstance is modeled as a real-valued variable the causality of the resistor is free.

$m T F$-The bondgraphic modulated transformer element. It inherets the effort and flow variables from the modulated direct TwoPort. The transformation constant is modeled as a real-valued variable. Some other bond graph references define the transformation constant as amplicification of effort from the inflow to the outflow. The transformer model has one causality stroke.

$m G Y$-The bondgraphic modulated

gyrator element. The bondgraphic modulated gyrator is a modulated direct Two Port element. It inherits the effort and flow variables from the modulated directed TwoPort. The gyrator constant is modeled as a real valued variable. The bond graph literature is not constant in the definition of the gyration constant. In this library the constant is is defined as the amplification of flow at the inflow to effort at the outflow. The gyrator has zero or two strokes.

$m S f$ - The modulated flow source is a modulated active OnePort element. It inherits the effort and a flow variable from the modulated active OnePort The modulated flow to be generated is modeled as a real-valued variables. The flow source has its causality stroke at the source.

\section{$I$-The bondgraphic linear inductor} element. The bondgraphic linear inductor is a passive OnePort element. It inherits the effort and the flow variables from the passive OnePort. The inductance is modeled as a parameter. The inductor model has a preferred causality at the element.

The normal force $F_{\mathrm{n}}$ can be descierd as:

$$
F_{n}=\frac{M_{g}+s_{1} M_{1}+s_{1} M_{10}+d_{1} x_{1}}{L(\sin \varphi-s \mu(\lambda) \cos \varphi)}
$$

The dynamic of the ABS models is definite with equations (4) and (5): 


$$
\begin{aligned}
& J_{1} \dot{x}_{1}=F_{n} r_{1} s \mu(\lambda)-d_{1} x_{1}-s_{1} M_{10}-s_{1} M_{1} \\
& J_{1} \dot{x}_{1}=\frac{M_{g}+s_{1} M_{1}+s_{1} M_{10}+d_{1} x_{1}}{L(\sin \varphi-s \mu(\lambda) \cos \varphi)} r_{1} s \mu(\lambda)-s_{1} M_{1}-d_{1} x_{1}-s_{1} M_{10} \\
& J_{2} \dot{x}_{2}=-F_{n} r_{2} s \mu(\lambda)-d_{2} x_{2}-s_{2} M_{20} \\
& J_{2} \dot{x}_{2}=\frac{M_{g}+s_{1} M_{1}+s_{1} M_{10}+d_{1} x_{1}}{L(\sin \varphi-s \mu(\lambda) \cos \varphi)} r_{2} s \mu(\lambda)-d_{2} x_{2}-s_{2} M_{20}
\end{aligned}
$$

Were: $\dot{x}_{1}$ and $\dot{x}_{2}$ are angular velocities of the upper and lower wheel, $r_{1}$ i $r_{2}$ are radiuses of the wheels. The torque moments $J_{1}$ and $J_{2}, d_{1}$ and $d_{2}$ are the coefficient of the viskosity friction, $M_{10}$ and $M_{20}$ are statistic friction, upper and under wheels, $M_{\mathrm{g}}$ is gravitational and shok absorber torque. The distance between the contact point of the wheels and the rotational axis of the balance lever is $\boldsymbol{L}$, the angle between the normal in the contact point and the line $\boldsymbol{L}$ is with notation $\varphi$.

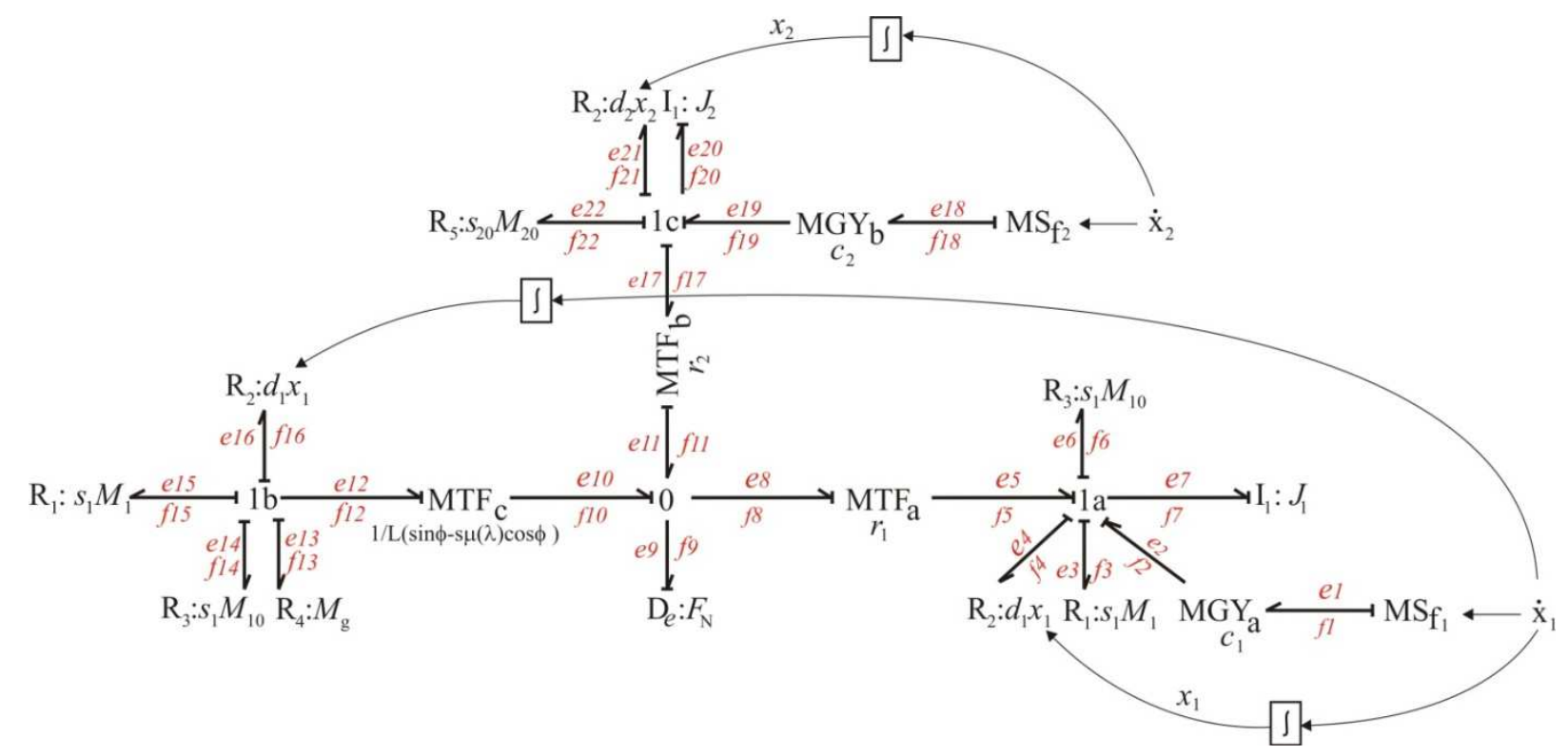

Fig. 3: Bond graph model of an ABS

The controlled variable is the wheel slip, so that it is of great importance to describe its dynamics in a proper manner. The wheel slip $\lambda$ is defined by: 


$$
\begin{aligned}
& \lambda=\left\{\begin{array}{l}
\frac{r_{2} x_{2}-r_{1} x_{1}}{r_{2} x_{2}}, r_{2} x_{2} \geq r_{1} x_{1}, x_{1} \geq 0, x_{2} \geq 0, \\
\frac{r_{1} x_{1}-r_{2} x_{2}}{r_{1} x_{1}}, r_{2} x_{2}<r_{1} x_{1}, x_{1} \geq 0, x_{2} \geq 0, \\
\frac{r_{2} x_{2}-r_{1} x_{1}}{r_{2} x_{2}}, r_{2} x_{2}<r_{1} x_{1}, x_{1}<0, x_{2}<0, \\
\frac{r_{1} x_{1}-r_{2} x_{2}}{r_{1} x_{1}}, r_{2} x_{2} \geq r_{1} x_{1}, x_{1}<0, x_{2}<0, \\
1, \quad \text { if } \quad x_{1}<0, x_{2} \geq 0, \\
1, \quad \text { if } \quad x_{1} \geq 0, x_{2}<0 .
\end{array}\right. \\
& \text { (9) }
\end{aligned}
$$

Corresponding switch function in Dymola is given in Fig.5:

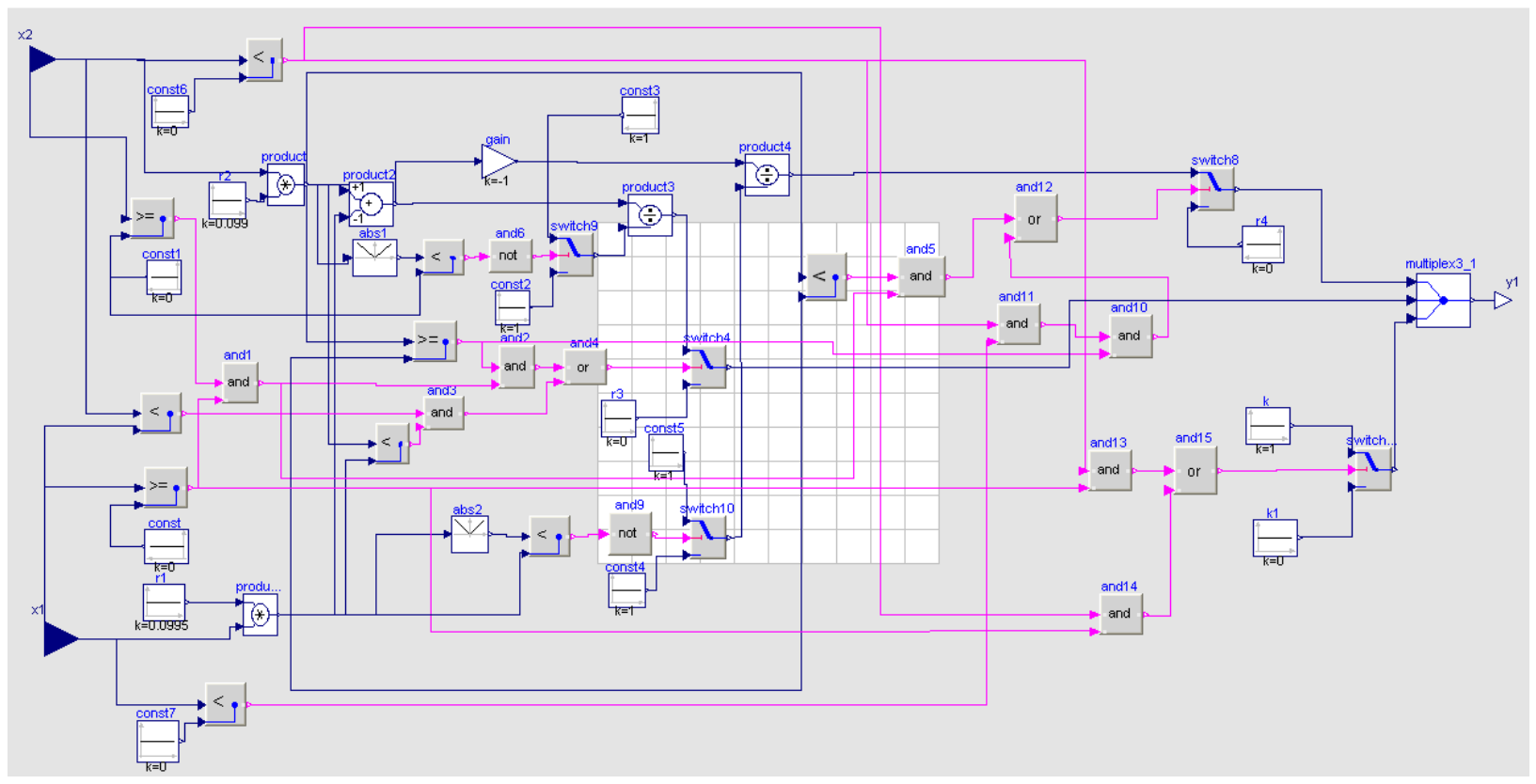

Fig.4. Function of lambda in Dymola

for all quarter vehicle model operating conditions.

The coefficient $\mu(\lambda)$ is defined by the following equation:

$\mu(\lambda)=\frac{w_{4} \lambda^{p}}{a+\lambda^{p}}+w_{3} \lambda^{3}+w_{2} \lambda^{2}+w_{1} \lambda$

(10) 


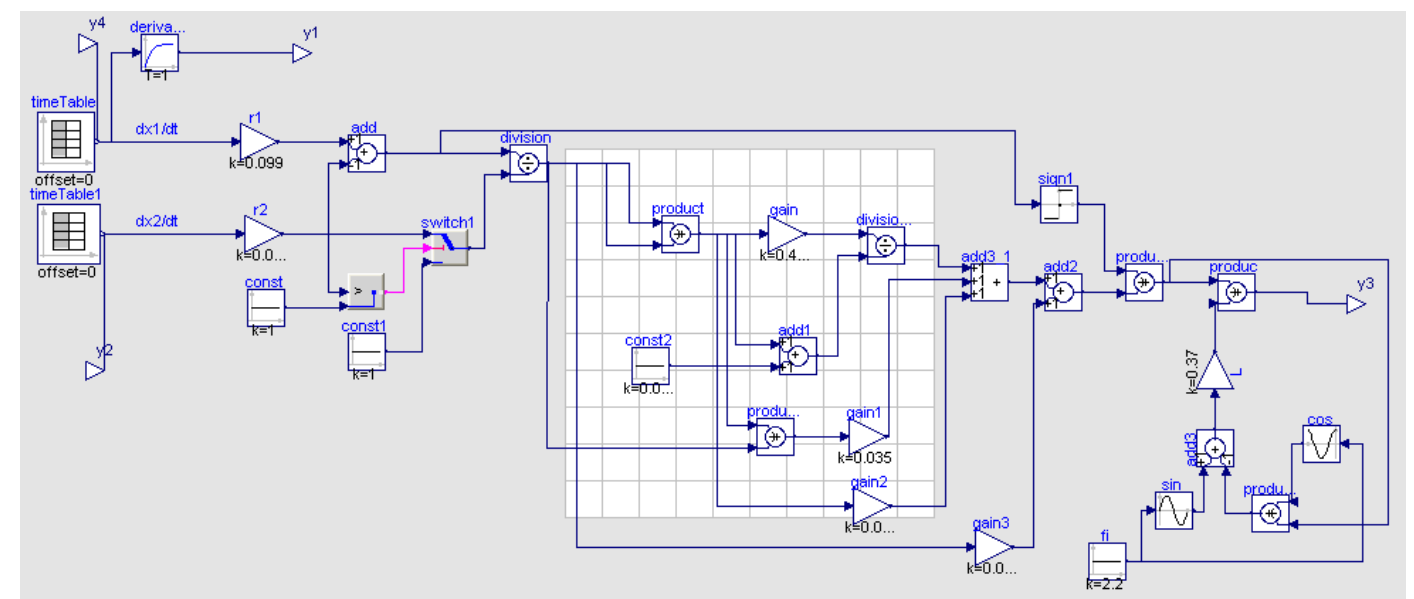

Fig. 5: Subfunction slip with functional velocities of wheel and road

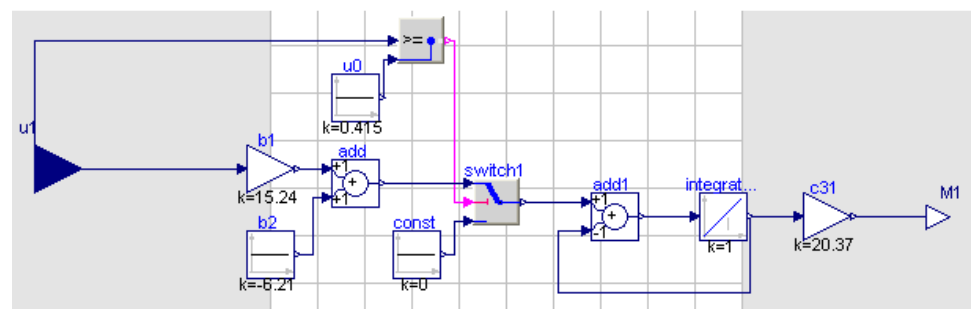

Fig. 6: Blocks of subfunctions $\mathrm{M}_{1}$

The simulation results are showen in follow pictures:

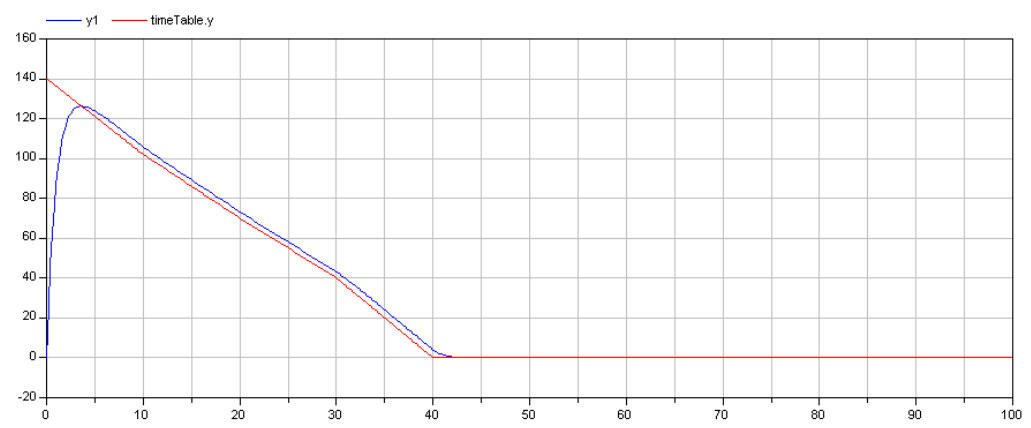

Fig. 7: Wheel velocity (red line) and acceleration (blue line)

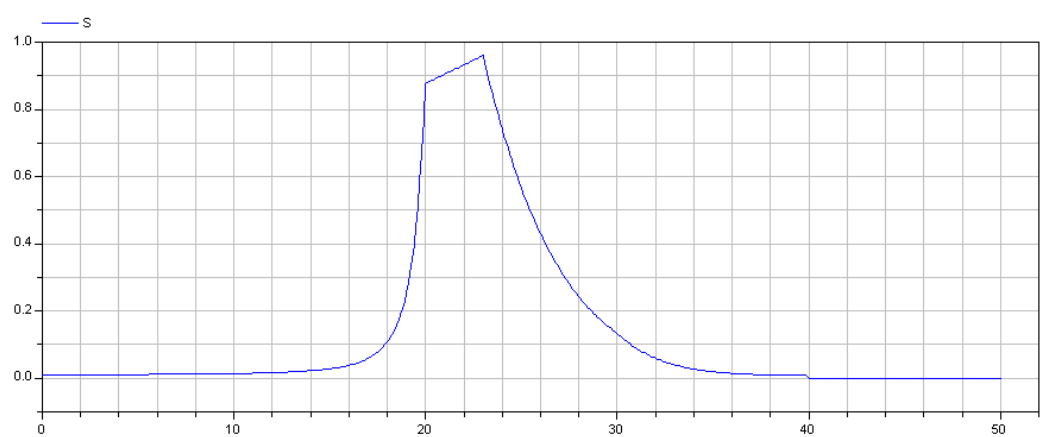

Fig. 8: Function of slip friction $(\mu)$ curves in function of time 


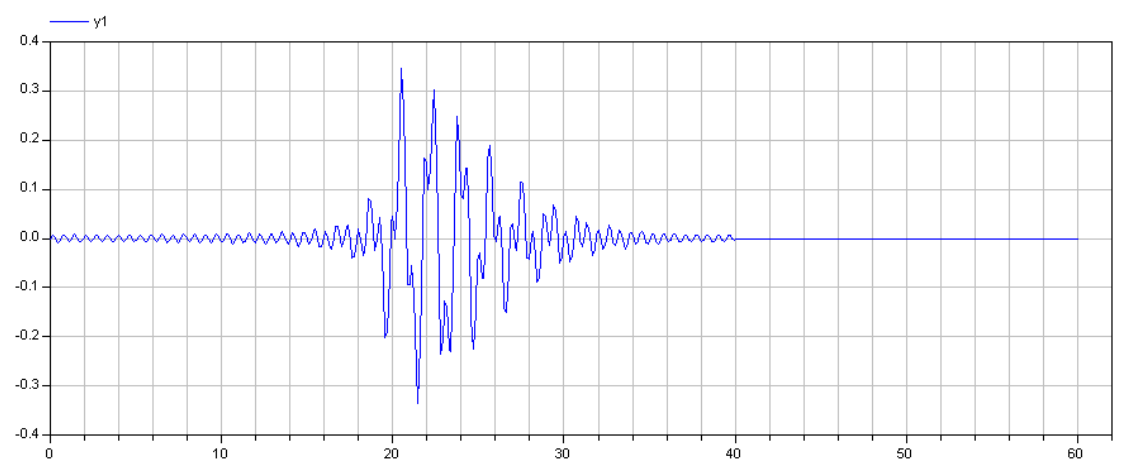

Fig 9: Function $\mu$ in function of the time

Distance $\mathrm{L}$ as an angle $\varphi$ and radiuses of the wheels are measured. Geometrical issues are given in following table:

\begin{tabular}{|c|c|c|c|c|c|c|c|c|c|c|}
\hline $\begin{array}{c}\mathrm{R} 1 \\
(\mathrm{~m})\end{array}$ & $\begin{array}{c}\mathrm{R} 2 \\
(\mathrm{~m})\end{array}$ & $\begin{array}{c}\phi \\
\left({ }^{\circ}\right)\end{array}$ & $\begin{array}{c}\mathrm{L} \\
(\mathrm{m})\end{array}$ & $\begin{array}{l}\mathrm{Mg} \\
(\mathrm{N})\end{array}$ & $\begin{array}{c}\mathrm{J}_{1} \\
\left(\mathrm{kgm}^{2}\right)\end{array}$ & $\begin{array}{c}\mathrm{J}_{2} \\
\left(\mathrm{kgm}^{2}\right)\end{array}$ & $\begin{array}{c}\mathrm{d}_{1} \\
\left(\mathrm{kgm}^{2} / \mathrm{s}\right)\end{array}$ & $\begin{array}{c}\mathrm{d}_{2} \\
\left(\mathrm{kgm}^{2} / \mathrm{s}\right)\end{array}$ & $\begin{array}{c}\mathrm{M}_{10} \\
(\mathrm{Nm})\end{array}$ & $\begin{array}{c}\mathrm{M}_{20} \\
(\mathrm{Nm})\end{array}$ \\
\hline 0,0995 & 0,099 & 65,61 & 0,37 & 19,62 & 0,00753 & 0,0256 & $1,87410^{-4}$ & $2,146810^{-4}$ & 0,032 & 0,0925 \\
\hline
\end{tabular}

Table 1: Parameter values used in simulation

\section{CONCLUSIONS}

In this paper are shown model of the hybrid bond graph ABS with simulations results. The mathetmatical description in nonlinear domen are modified in hybrid bond graph scheme, and new verification of the proposed approach in the management of digital simulation in Dymola was performed and real experiment. The introduction of the fuzzy control in ABS, knows it significantly improves the characteristics of the nonlinear system, as it is shown in simulation results. It is confirmed the good performance of the control algorithm in comparison with traditional solutions.

\section{REFERENCE:}

[1] Inteco, "The laboratory Anti-lock Braking System controlled from PC"-User's Manual, (2008) available at www.inteco.com.pl

[2] D. Antić, V. Nikolić, D. Mitić, M. Milojković and S. Perić, "Sliding Mode Control of Antilock Braking System: An Overview", Facta Universitatis Series: Automatic Control and Robotics, vol. 9, no. 1, pp. 41-58, 2010.
[3] S. Perić, D. Antić, V. Nikolić, D. Mitić, M. Milojković, S. Nikolić, “A New Approach to the sliding mode control design: Anti-Lock Braking System as a case", Journal of The Electrical Engineering, Vol. 65, No. 1, pp. 3743, 2014.

[4] D. Antić, V. Nikolić, D. Mitić, M. Milojković and S. Perić (2010a), "Sliding Mode Control of Anti-lock Braking System: An Overview“, Facta Universitatis Series: Automatic Control and Robotics, Vol. 9, No. 1, pp. 41-58.

[5] D. Antić, V. Nikolić, D. Mitić, M. Milojković and S. Perić (2010b), "Sliding Mode Control of Anti-lock Braking Systems: An Overview", $X$ Trienal International SAUM Conference on Systems, Automatic Control and Measurements, SAUM 2010, pp. 41-48.

[6] Mitić, D., D. Antić, S. Perić, M. Milojković and S. Nikolić (2011), "Sliding Mode Control of Anti-lock Braking System Based on Reaching Law Method, XLVI International Scientific Conference on Information “, Communication and Energy Systems and Technologies, ICEST 2011 (unpublished).

[7] D.Mitić, D. Antić, S. Perić, M. Milojković, S. Nikolić (2012), "Fuzzy sliding mode control for anti-lock braking systems", Applied Computational Intelligence and Informatics (SACI), Vol. 7, pp. $217-222$ 
[8] T.K. Bera, K. Bhattacharya, $\underline{\text { A.K. }}$ Samantaray (2011), "Evaluation of antilock braking system with an integrated model of full vehicle system dynamics“, Simulation Modelling Practice and Theory, Vol. 19, Issue 10, pp. 2131-2150

[9] Yesim Oniz, Erdal Kayacan and Okyay Kaynak (2007), "Simulated and Experimental Study of Antilock Braking System Using Grey Sliding Mode Control", Systems, Man and Cybernetics, 2007. ISI, IEEE International Conference, pp. 90 - 95 